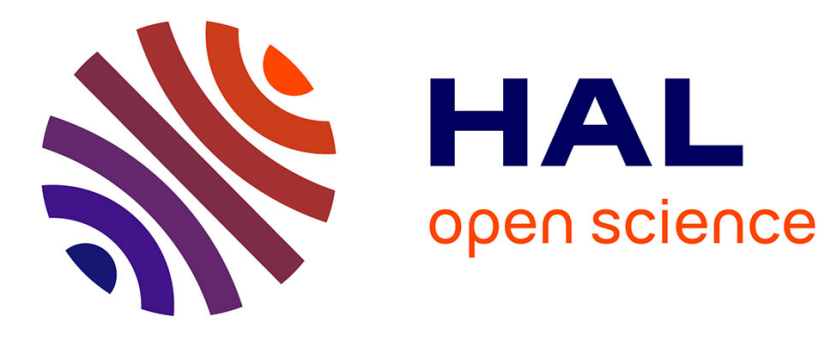

\title{
Emerging Schistosomiasis in Europe: A need to quantify the risks
}

Julien Kincaid-Smith, Olivier REY, Eve Toulza, Antoine Berry, Jérôme

Boissier

\section{- To cite this version:}

Julien Kincaid-Smith, Olivier REY, Eve Toulza, Antoine Berry, Jérôme Boissier. Emerging Schistosomiasis in Europe: A need to quantify the risks. Trends in Parasitology, 2017, 33 (8), pp.600-609. 10.1016/j.pt.2017.04.009 . hal-01598398

\section{HAL Id: hal-01598398 \\ https://hal.science/hal-01598398}

Submitted on 3 Feb 2021

HAL is a multi-disciplinary open access archive for the deposit and dissemination of scientific research documents, whether they are published or not. The documents may come from teaching and research institutions in France or abroad, or from public or private research centers.
L'archive ouverte pluridisciplinaire HAL, est destinée au dépôt et à la diffusion de documents scientifiques de niveau recherche, publiés ou non, émanant des établissements d'enseignement et de recherche français ou étrangers, des laboratoires publics ou privés. 


\title{
Emerging Schistosomiasis in Europe: A Need to Quantify the Risks
}

\author{
Julien Kincaid-Smith, ${ }^{1, y}$ Olivier Rey, ${ }^{1, y}$ Eve Toulza, ${ }^{1}$ Antoine Berry, ${ }^{2}$ and Jérôme Boissier ${ }^{1,}{ }^{*}$
}

\author{
${ }^{1}$ Univ. Perpignan Via Domitia, IHPE UMR 5244, CNRS, IFREMER, Univ. Montpellier, F-66860 Perpignan, \\ France \\ ${ }^{2}$ Service de Parasitologie-Mycologie, CHU Toulouse and Centre de Physiopathologie de Toulouse \\ Purpan, INSERM U1043, CNRS UMR5282, Université de Toulouse, Toulouse, France
}

'These authors made equal contributions.

*Correspondence: boissier@univ-perp.fr (J. Boissier).

\begin{abstract}
The recent recurrent outbreaks of urogenital schistosomiasis in the south of Europe were unanticipated and caught scientists and health authorities unpre-pared. It is now time to learn lessons from these outbreaks and to implement concrete procedures in order to better quantify the risks and prevent future outbreaks of schistosomiasis in Europe. In this context, we propose a reflection on the factors that currently hamper our ability to quantify these risks and argue that we are incapable of predicting future outbreaks. We base our reflexion on an ecological two-step filter concept that drives host-parasite interactions, namely the encounter and the compatibility filters.
\end{abstract}

\section{Trends}

Global changes promote the establishment and spread of infectious diseases worldwide. Several tropical and subtro- pical vector-borne diseases have recently emerged in more temperate geographical areas, demonstrating that they need further considerations. An autochthonous urogenital schisto-somiasis outbreak has recently been identified in Southern Europe (Corsica, France). The causative parasitic agent is a hybrid between a human-specific and a livestock-specific schistosome species. Quantifying the emerging risk of vec-tor-borne disease requires knowledge of the ecological characteristics of parasites and their potential vectors as well as of the interactions between protagonists in Northern latitudes. Host-parasite interactions are driven by an ecological two-step filter con-cept (the encounter and the compat-ibility filters). Global changes and hybridization may affect both filters, hence hampering our ability to quantify the risk of future emergence. Thus, we are still incapable of predicting future outbreaks, and new tools need to be developed.

\section{Schistosomiasis Outbreaks in Europe}

Global changes, including both natural and anthropogenic environmental modifications, pro-mote the spread of exotic pathogens worldwide and disease outbreaks [1]. In particular, with the ongoing rise in temperature and the intensification of human activities, it is expected that tropical and subtropical vector-borne diseases will expand to higher latitudes [2-6]. So far, concrete cases of autochthonous transmission of tropical infectious diseases in temperate areas remain scarce. The most alarming examples of pathogen geographical range expansions are the recent cases of locally acquired arthropod-borne diseases such as dengue, malaria, and chikungunya in southern Europe [7-10]. 
Climate change and trade of car tyres promoted the establishment of the mosquito vector species around the Mediterranean Sea, hence allowing the parasites to complete their life cycles and emerge locally. To face the risk of arthropod-borne diseases, the European Union (EU) established the VBORNET network in 2010. This One Health consortium mobilized both entomological and public health specialists to assist the European Centre for Disease Prevention and Control (ECDC). This network was completed by the VectorNet project in 2014 to include animal disease agents. Today, upto-date distribution maps of mosquitoes, ticks, and sandflies are freely available on the website of the ECDC. In addition to the risk map, the ECDC has published guidelines for the surveillance of native and invasive mosquitoes in Europe [11,12]. These resources paved the way to concrete and applied operational processes for a better surveillance of mosquitoes and to prevent future outbreaks.

For several reasons, the risks of snail-borne diseases in Europe have been overlooked so far. First, until very recently, freshwater ecosystems received less ecological attention than terres-trial systems [13]. Second, the expansion, and ultimately the establishment, of snail intermedi-ate host species that have coevolved with parasites from tropical countries to Europe is expected to be limited because of the low dispersal ability of freshwater snails. However, in March 2014, clusters of human urogenital schistosomiasis cases, transmitted through fresh-water Bulinus snails, were simultaneously diagnosed in French and German hospitals [14-16].

These patients had never visited a Schistosoma haematobium-endemic country (i.e., Africa, Arabian Peninsula), but all the patients had spent their holidays in Corsica in August 2013. Corsica is a favourite destination for tourists from Europe and overseas, and more specifically during summer. All the infected individuals had been in contact with the Cavu River (southern Corsica) which is famous for its crystalline and warm natural pools. Subsequently, the INVS (Institut National de Veille Sanitaire) and the ECDC published a rapid risk assessment. Following a massive campaign for diagnosis in April 2015, more than 100 further cases which had contracted the disease during summer 2013 were reported in France. Surprisingly, after intensive screening for the presence of the parasite, no Bulinus truncatus snails from the Cavu river were found to be infected with schistosomes, highlighting the difficulty of detecting the parasite in the field [17]. Moreover, no potential animal reservoir host was found in the vicinity of the river [17]. However, during the summer of 2015 a new case of acute endemic schistosomiasis was acquired in Corsica, indicating that transmission is persisting locally and pointing out the risk for further infections [18]. In line with this outbreak, the rapid risk assessment of the ECDC stated: "The autochthonous transmission of S. haematobium in Corsica in 2013 is a local public health event that highlights a potential risk for other receptive areas of southern Europe. Therefore, there is a need to consider enhancing epidemiological surveillance for schistosomi-asis in the EU.". Contrary to arthropod-borne diseases, the emergence of schistosomiasis in Europe was unexpected, and both the scientific community and health authorities were caught unprepared. We discuss here the reasons why we are currently incapable of predicting future outbreaks of this neglected but severe tropical disease in Europe and address several directions that would greatly improve our ability to better evaluate these risks. We base our reflection on the fundamental two-step filter concept, including the encounter and the com-patibility filters, as first proposed by Louis Euzet and Claude Combes in the 2000 s $[19,20]$ and examine how global changes are expected to alter these filters and hence increase the risk of schistosome parasites establishing and spreading throughout Europe.

\section{Host-Parasite Association Filters}

Host-parasite interactions can be analysed through the concept of association filters. In all systems formed by two organisms, natural selection tends to maximise their fitness indepen-dently [21]. In a host-parasite couple, a filter can be seen as a virtual phenotype defined by both the genome of the parasite and the genome of the host [19]. At the parasite level, filters need to be open to accomplish 
their life cycle, therefore natural selection will tend to select genes allowing both the encounter (encounter filter open) and the survival of the parasite (compatibility filter open) associated with its host. On the contrary, hosts will tend to close these two filters, and natural selection will select genes allowing them to avoid (encounter filter closed) and kill (compatibility filter closed) the parasites. When these filters are synchronously opened in a particular area, and for a particular host-parasite association, there is a potential risk for disease emergence. Evaluating the status of these two filters (open or closed) offers the opportunity to quantify the risk for schistosomiasis emergence in Europe.

\section{Encounter Filter}

The encounter requires spatial and temporal overlap between the host and the parasite. Quantifying the risk of emergence and spread of schistosomes in Europe thus partially depends on our knowledge concerning (i) the geographical distribution of all potential intermediate snail hosts for the parasites to complete their life cycle locally, and (ii) the dispersion of parasites through their definitive hosts and in particular humans.

\section{What Do We Really Know about the Distribution of Schistosome Intermediate Snail Hosts in Europe?}

The answer is: very little. Among the 2090 freshwater snail species for which the geographical range was documented in Europe, Planorbarius metidjensis and B. truncatus are intermediate hosts for schistosome species in Africa [22], especially the human-infecting species S. haema- tobium. However, most of the sampling references for these two host species are out of date [22]. Moreover, snail populations are highly dynamic in space and time (Box 1). P. metidjensis is expected to be present in all the Iberian Peninsula (Spain and Portugal) and has never been observed elsewhere in Europe [22]. Two recent records confirm the current abundance of this snail species in the south of Spain (in the province of Huelva and in Almeria) $[23,24]$. B. truncatus is expected to be present in all the Mediterranean islands, in the Atlantic and Mediterranean coastal zones of the Iberian Peninsula, in the western coastal zone of Italy, in Greece, and in the south of France [22]. In southern Spain, B. truncatus has been recorded recently in the province of Huelva [23], in Almeria and Alicante [25], and in northern Spain, in Catalonia [26] and in Galicia provinces [27]. In France, B. truncatus is abundant in the island of Corsica [28] and has been sparsely observed in the south of the mainland, in the piedmont of the Pyrenees [29] and around Montpellier [30]. All these records are sporadic and are clearly insufficient to quantify the spreading potential of $\mathrm{S}$. haematobium in Europe. Determining the distribution of intermediate snail hosts is hindered by the available methods used to collect and identify species. Classically, freshwater snail detection is performed by scooping the grasses in the bank of the water bodies and turning the stones at the bottom of the river. Then, the identification of the snails to the species level is anything but trivial and requires thorough malacological knowledge. Such an approach is tedious and time consuming and there is thus an urgent need to develop more efficient tools to improve extensive spatial and temporal snail surveys.

Moreover, there is also very little information concerning the ability of $\mathrm{S}$. haematobium to infect alternative local European snails. Host shifts can occur when parasites disperse to new environments in which their natural primary hosts are absent [31]. Schistosomes, and especially S. haematobium, are known to be specific to their snail hosts in their native range, and host-switching is thus expected to be limited [32]. However, S. haematobium host-switching has promoted an outbreak of urogenital schistosomiasis in India in the middle of the last century [33]. In 1952, urogenital schistosomiasis foci were reported in Gimvi village (Bombay State), with more than 200 people excreting typical S. haematobium terminal spine eggs [34]. In response to this unexpected outbreak, notably due to the complete absence of the known potential intermediate host vectors in this area, Gadgil \& Shah [35] experimentally exposed several local snail species to $\mathrm{S}$. haematobium miracidia collected from the 
urine of infected patients. Against all odds, Ferrissia tenuis was successfully infected and produced schisto-some cercariae [35]. The genus Ferrissia is widely distributed in Africa but has never been shown to host schistosome parasites. This outbreak of $\mathrm{S}$. haematobium out of its native range clearly indicates that even for apparently highly specific parasites, shifts towards phylogeneti-cally distant hosts may occur. Finally, it is worth stressing that, like Bulinus, the genus Ferrissia belongs to the family Planorbidae, which is widely distributed across Europe.

\section{Where Does the Risk Come from?}

The dispersal of pathogens by air travel and subsequent importation risks in Europe has already been inferred for some arthropod-borne disease such as dengue [36]. In particular, authors quantified the importation risks of dengue into Europe by considering in their model the volume of air-travellers arriving from dengue-infected areas and European cities in which the potential arthropod vector (Aedes albopictus) is present. They found that, in 2010, Milan, Rome, and Barcelona were hotspots for dengue importation and autochthonous outbreaks, especially from August to October [36]. Concerning schistosomes, the EuroTravNet consortium has recently synthesized 5 years (2008-2012) of travelrelated illness $(n=32136)$ [37]. Schistoso-miasis ranked 12th in the imported disease category (with malaria ranking first), with around 22 cases for 1000 ill patients. Importantly, this study also revealed that patients harbouring schistosomiasis infection are represented in all categories of travellers: business (9\%), immi-gration (18\%), missionary/volunteer (33\%), tourism (21\%), and people visiting friends and relatives (16\%); a majority came from sub-Saharan Africa (74\%). Considering that around 100 million passengers enter Europe on commercial flights every year [36] the risks for other schistosome outbreaks is a real concern [38-41].

S. haematobium is endemic in 53 countries, mostly in Africa and the middle-East [42]. The parasites responsible for the recent outbreak in Corsica were genetically closely related to parasitic populations from Senegal [17]. Several sociological elements also support the hypo-thetical Senegalese origin of this parasite. First, urogenital schistosomiasis is present across Senegal, and its prevalence is estimated to be $25 \%$ at the national scale [43]. Second, Senegal is a former French colony, and these two countries still have strong commercial and political relationships with important bidirectional population flows. With around 100000 French tourists every year, Senegal ranks 35th for preferred French tourist destinations, and $50 \%$ of tourists in Senegal are from France. In the other direction, France is the first destination for Senegalese people in Europe.

The probability of an encounter between the parasite and its mollusc host is also related to the length of time that the infected patient will be able to excrete eggs. In the case of schistosomiasis, this duration is often very long for two main reasons. First, the diagnosis of the infection is difficult; it may be delayed or even not performed (Box 2). Second, the lifetime of the adult parasite in its host is long, from 3 to 10 years and up to 40 years [44]. By comparison, this duration of transmission is much longer than for arboviruses, in which the viremic phase of transmission lasts only a few days.

\section{Compatibility Filter}

Overlap in host and parasite distribution (i.e., open encounter filter) is necessary but not sufficient to allow the parasites to complete their life cycles. The compatibility filter also needs to be open $[19,20]$. A host is defined as compatible to a parasite if it provides adequate resource and is incapable of eliminating the parasite with its defense mechanisms. Compatibility between schistosomes and their intermediate snail hosts results from a complex pheno-type-to-phenotype interaction between each pair of individuals (parasite and snail) [45]. The compatibility polymorphism is widely documented between S. mansoni (responsible for the human mesenteric schistosomiasis) and its snail host, Biomphalaria glabrata, at both the populational and molecular levels [46]. Conversely, few studies 
have yet investigated the levels and mechanisms of compatibility between $\mathrm{S}$. haematobium and Bulinus or Planorbarius snails. We here synthesized all published studies that have experimentally tested the compatibility between various host/parasite strains (see Table S1 in the supplemental information online). Concerning the $\mathrm{S}$. haematobium-B. truncatus pair, most studies have quantified the compati-bility between parasite and snail strains from Africa (either in sympatry or in allopatry). Our synthesis indicates that, at the national scale, sympatric associations are more compatible than allopatric ones in Cameroon [47] - which is in contrast to results obtained in Niger [48]. Moreover, considering that geographic and genetic distances may be correlated for both snail and parasite, we might expect a negative correlation between geographic distances and compatibility under a coevolving scheme. However, we found no significant relationship between geographic distance between parasite and host strains and compatibility (Spearman correlation test; $n=32 ; r=\ldots 0.32 ; P>$ 0.05 ) at the African continent level. Thus, there is no congruence between the coevolutionary history of snails and parasites and their compatibility. Such disconnection clearly hampers our ability to predict which parasite populations are more prone to settle in a given geographic locality, and more particularly which parasite populations from endemic countries constitute the greatest threat to Europe.

In this regard, few and somewhat dated studies have tested the compatibility between parasitic strains from Africa and snail intermediate hosts from Europe. Capron and collaborators [49] found high levels of compatibility between B. truncatus from France (Corsica) and an S. haematobium strain from Algeria (52.6\% of snails were infected when exposed to five miracidia). In the context of the first emergence of schistosomiasis in Portugal in the 1920s, some authors revealed that local B. truncatus snails were compatible with parasites coming from Guinea Bissau or Mozambique but not from Angola (Table S1). Compatibility between S. haematobium from several African countries and P. metidjensis from Portugal and Spain was also experimentally quantified recurrently [50-52]. All of these studies failed to infect snails, suggesting that $\mathrm{P}$. metidjensis from Europe is not compatible with $\mathrm{S}$. haematobium from Africa. This was surprising given that some local wild populations of $P$. metidjensis were found to be naturally infected with S. haematobium at the time of the schistosomiasis outbreak in the 1920s [53]. More recently, some authors found that snail size was critical for infecting P. metidjensis with S. haematobium and concluded that the failure of experimental infestation of P. metidjensis from Portugal could have resulted from the use of nonadequate snail sizes [54-58]. Another hypothesis would be that P. metidjensis from Portugal is indeed incompatible with pure $S$. haematobium, and that wild populations of P. metidjensis in Portugal were actually infected by hybrids of $\mathrm{S}$. haematobium and S. bovis, the latter being present in southern Europe [59]. Hybridization between schistosome species is indeed known to widen the snail host spectrum [60]. This last hypothesis is particularly relevant in the European context because P. metidjensis is abundant in the Iberian Peninsula, and S. haematobium S. bovis hybrids were identified in several West African countries (Senegal, Mali, Benin, and Niger) [61-64] and, more recently, during the outbreak in Corsica [17,62].

\section{Effects of Global Changes on the Encounter and the Compatibility Filters}

Quantifying the risks of schistosomiasis emergence in Europe is highly dependent on our ability to predict where and when filters will be opened synchronously (see Figure 1). In the next section we examine how global changes may affect the opening and dynamics of these two filters.

The increases in human activities and movements are by far the most obvious factors that may open the encounter filter by increasing contact probabilities between parasites and snail intermediate hosts. The accruing human bidirectional flows between Europe and endemic tropical and subtropical areas increase the possibility that infected travellers import into Europe parasite strains that are capable of infecting local potential hosts (i.e., B. truncatus or P. metidjensis) or switch to a novel local snail host 
species. Finally, increased parasite movements might also promote hybridization events between strains or species. Hybridization in the genus Schistosoma is common [65] and can alter the compatibility filter by diversifying the range of both intermediate and final hosts [66]. It is also hypothesized that hybridization may foster adaptation to novel environmental conditions and hence facilitate the establishment and spread of parasites northward [66].

Climatic change is another aspect that can affect both filters. More specifically, rising temper-atures are known to impact the distribution and abundance of freshwater snails, thus modifying their potential geographical distribution. Such influence of climate change on the distribution of coevolved snail hosts has been predicted in Africa $[67,68]$ but not in Europe. Together with an increase in parasite dispersion, this geographical expansion is expected to provide optimal environmental conditions (both biotic and abiotic) for the parasite to establish and spread. Changes in seasonality may also have a huge impact on the encounter filter by extending seasons during which the parasite larvae may be emitted by the snails, hence favouring infections of definitive hosts. At the compatibility filter level, temperature increase is known to affect snail susceptibility to schistosomes, reversing a resistant to a compatible phenotype [69]. Until now, few studies have investigated the effect of other global changes on the encounter and compatibility filters in schistosomes. However, it is likely that other factors, such as water quality (e.g., pollution) or river fragmentation, might have impacts on the ability of parasites to infect both intermediate and final hosts, either by affecting compatibility or favouring contacts.

\section{Concluding Remarks and Future Perspectives}

Today we are incapable of inferring the current and future risks of schistosomiasis outbreaks in Europe without answering a few specific questions (see Outstanding Questions). First, it is urgent to determine the geographic distribution of the snail intermediate host populations and to monitor their spatiotemporal dynamics. For this purpose, several tools are currently available. (i) Spatial statistical models have recently been used to predict the theoretical niche and infer the potential spatial distribution of schistosome intermediate snail species in endemic countries [70,71]. (ii) Environmental DNA (eDNA) is promising to detect both parasites and vectors at large spatial and temporal scales [72]. eDNA is widely used in aquatic ecology for the detection of invasive species, or species of interest, or to evaluate ecosystem biodiversity [73]. Recently eDNA has been successfully used for detecting trematode parasites infecting frogs [74], bird schistosomes [75], invasive mosquito vectors (Aedes albopictus) [76], and for inferring myxo-zoan diversity [77]. Combined with punctual malacological surveys and spatial modelling, the eDNA approach would greatly improve our ability to develop 'realtime' risk maps of schistosomiasis transmission in both Europe and all endemic countries [78]. (iii) Finally, the susceptibility level of possible European intermediate hosts for different parasite strains is largely unexplored. Considering the absence of links between geographic distance and compatibility, and without experimental evidence, it is not possible to predict which parasite strains have the highest introduction risk level in Europe. Experimental tests between several parasite strains and several snail hosts are hence needed to address this question.

In the light of our synthesis, it clearly appears that we are far from being able to quantify the risk of schistosomiasis emergence in Europe. Importantly however, the current risk of schistoso-miasis outbreaks in Europe compared to arthropod-borne diseases needs to be nuanced for several reasons. First, contact with infected freshwater is a prerequisite for humans to be infected. In Europe, the relationship to freshwater and water contacts are mostly limited to recreational or agricultural activities. Second, the sanitation networks of the European countries greatly limit possible dissemination of schistosomiasis to urban areas. Indeed, helminth eggs are easily removed during water treatment. Systems involving primary and secondary sewage treatment without chlorination are highly successful for removing schistosome eggs (99.5\% of eggs are removed) [79]. However, contrary 
to arthropod-borne diseases, the persistence of the parasite in hosts is very high. In humans, the adult parasite worms can live several decades, emitting eggs throughout their host's lifetime. The fact that several human cases are asymp-tomatic makes parasite detection problematic. Thus, although the parasites are expected to persist little in the water, they are expected to persist over long periods within their hosts with recurrent swarms of infecting stages in the environment. Concerning the snail intermediate host, the lifetime of infected snails has been documented in the context of a subtropical climate but not in more temperate countries. For instance, we know that adult Aedes mosquitoes cannot persist over a winter season [80], whereas we still do not have a clue whether infected Bulinus snails are able to persist over that period. This calls for more ecological research to better appreciate the interactions between schistosomes, their hosts, and the continental environment to understand how global changes may promote the emergence of autochtho-nous schistosomiasis in Europe.

\section{Outstanding Questions}

What are the ecological characteristics of habitat of the schistosome interme-diate in Europe? What is the spatial repartition of schis-tosome intermediate hosts in Europe? Are schistosomes able to expand their snail intermediate host range to Euro-pean endemic snails? Are schistosome-infected snails able to persist over a winter season in Europe?

What are the schistosome and mollusc intermediate host life history traits in temperate conditions? Are hybrid schistosomes more virulent than parental species?

Is the invasive capacity of schisto-somes limited to hybrid parasites? Are all African schistosome strains able to emerge in Europe?

What could be the future distribution of schistosome intermediate hosts and host-parasite interactions as a conse-quence of climate change?

Can we quantify the risk of emergence by measuring human movement?

Are the public health organizations ready to control schistosomiasis out-breaks in southern Europe?

\section{Acknowledgment}

This work was supported by the Anses (Agence nationale de sécurite sanitaire de l'alimentation, de l'environnement et du travail). The authors would thank members of the Agence Régionale de Santé de Corse. 


\section{References}

1. Kim, K.H. et al. (2014) A review of the consequences of global climate change on human health. J. Environ. Sci. Health 32, 299- 318

2. Bouzid, M. et al. (2014) Climate change and the emergence of vector-borne diseases in Europe: case study of dengue fever. BMC Public Health 14, 781

3. Rogers, D.J. and Randolph, S.E. (2006) Climate change and vector-borne diseases. Adv. Parasitol. 62, 345-381

4. Schaffner, F. et al. (2013) Public health significance of invasive mosquitoes in Europe. Clin. Microbiol. Infect. 19, 685-692

5. Schaffner, F. et al. (2013) Development of guidelines for the surveillance of invasive mosquitoes in Europe. Parasites Vectors 6, 209

6. Schaffner, F. and Mathis, A. (2014) Dengue and dengue vectors in the WHO European region: past, present, and scenarios for the future. Lancet 14, 1271-1280

7. Rezza, G. et al. (2007) Infection with chikungunya virus in Italy: an outbreak in a temperate region. Lancet 370, 1840-1846

8. Schaffner, F. et al. (2014) Autochthonous dengue emphasises the threat of arbovirosis in Europe. Lancet 14, 1044

9. La Ruche, G. et al. (2010) First two autochthonous dengue virus infections in metropolitan France, September 2010. Euro Surveill. 15, 19676

10. Gould, E.A. et al. (2010) First cases of autochthonous dengue fever and chikungunya fever in France: from bad dream to reality! Clin. Microbiol. Infect. 16, 1702-1704

11. European Centre for Disease Prevention and Control (ECDC) (2014) Guidelines for the Surveillance of Native Mosquitoes in Europe, ECDC

12. European Centre for Disease Prevention and Control (ECDC) (2012) Guidelines for the Surveillance of Invasive Mosquitoes in Europe, ECDC

13. Puth, L. and Post, D.M. (2005) Studying invasion: have we missed the boat? Ecol. Lett. 8, 715-721

14. Berry, A. et al. (2014) Schistosomiasis haematobium, Corsica, France. Emerg. Infect. Dis. 20, 15951597

15. Holtfreter, M.C. et al. (2014) Schistosoma haematobium infec-tions acquired in Corsica, France, August 2013. Euro Surveill. 19, pii=20821

16. Boissier, J. et al. (2015) Schistosomiasis reaches Europe. Lancet 15, 757-758

17. Boissier, J. et al. (2016) Outbreak of urogenital schistosomiasis in Corsica (France): an epidemiological case study. Lancet Infect. Dis. 16, 971-979

18. Berry, A. et al. (2016) Evidence for a permanent presence of schistosomiasis in Corsica, France, 2015. Euro Surveill. 21, pii $=30100$

19. Combes, C. (2001) Parasitism: The Ecology and Evolution of Intimate Interactions, University of Chicago Press

20. Euzet, L. and Combes, C. (1980) Les problèmes de l'espèce chez les animaux parasites. Mémoires Soc. Zool. France 40, 239-285

21. Quigley, B.J. et al. (2012) The mode of host-parasite interaction shapes coevolutionary dynamics and the fate of host coopera-tion. Proc. Biol. Sci. 279, 3742-3748

22. Welter-Schultes, F. (2012) European Non-Marine Molluscs, a Guide for Species Identification, Planet Poster Editions

23. Talaván Gómez, J. and Talaván Serna, J. (2006) Notas sobre la malacofauna continental de Murcia y Almeráa. Spira 2, 27-36

24. Perez-Quintero, J.C. et al. (2004) Los moluscos de las aguas continentales de la provincia de Huelva. Iberus 22, 19-31 
25. Martínez-Ortí, A. et al. (2015) Dos nuevas localizaciones para España de Bulinus truncatus (Audouin, 1827) (Gastropoda, Pla-norbidae), hospedador intermediario de Schistosomiasis urinaria. Arxius de Miscellània Zoològica 13, 25-31

26. Bech, M. (1990) Fauna malacològica de Catalunya. Molluscs terrestres i d'aigua dolça. Treb. Inst. Cat. Hist. Nat. 12, 1-229

27. Rolán, E. et al. (1987) Fauna malacolágica de los estuarios- lagoones y sus variaciones por cambios de salinidad. Iberus 1, 59-65

28. Doby, J.M. et al. (1966) Snails and bilharziasis in Corsica. Distri-bution, frequency and biology of Bulinus truncatus. Ann. Para-sitol. Hum. Comp. 41, 337-349

29. Michaud, A. (1829) Physa contorta. Bull. Soc. Linn. Bordeaux 3, 268

30. Callot-Girardi, H. (2015) Contribution à la connaissance des mollusques dulcicoles de France. Avenionia1 152-162

31. Lymbery, A.J. et al. (2014) Co-invaders: The effects of alien parasites on native hosts. Int. J. Parasitol. Parasites Wildlife 3, 171-177

32. Rollinson, D. and Simpson, A.J.G. (1987) The Biology of Schis-tosomes. From Genes to Latrines, Academic Press

33. Southgate, V.R. and Agrawal, M.C. (1990) Human schistosomi-asis in India? Parasitol. Today 6, 166168

34. Gadgil, R.K. and Shah, S.N. (1952) Human schistosomiasis in India. Discovery of an endemic focus in the Bombay State. Indian J. Med. Sci. 6, 760-763

35. Gadgil, R.K. and Shah, S.N. (1955) Human schistosomiasis in India. II. Infection of snails with Schistosoma hematobium. Indian J. Med. Res. 43, 695-701

36. Semenza, J.C. et al. (2014) International dispersal of dengue through air travel: importation risk for Europe. PLoS Negl. Trop. Dis. 8, e3278

37. Schlagenhauf, P. et al. (2015) Travel-associated infection pre-senting in Europe (2008-12): an analysis of EuroTravNet longitu-dinal, surveillance data, and evaluation of the effect of the pretravel consultation. Lancet 15, 55-64

38. Beltrame, A. et al. (2016) Schistosomiasis screening of travelers to Corsica, France. Emerg. Infect. Dis. 22, 159-160

39. Gautret, P. et al. (2015) Local and international implications of schistosomiasis acquired in Corsica, France. Emerg. Infect. Dis. 21, 1865-1868

40. Gautret, P. et al. (2016) Schistosomiasis screening of travelers to Corsica, France. Emerg. Infect. Dis. 22, 160-161

41. de Laval, F. et al. (2014) Human schistosomiasis: an emerging threat for Europe. Lancet 384, 10941095

42. Chitsulo, L. et al. (2000) The global status of schistosomiasis and its control. Acta Trop. 77, 41-51

43. Schur, N. et al. (2011) Geostatistical model-based estimates of Schistosomiasis prevalence among individuals aged $</=20$ years in West Africa. PLoS Negl. Trop. Dis. 5, e1194

44. Colley, D.G. et al. (2014) Human schistosomiasis. Lancet 383, 2253-2264

45. Theron, A. et al. (2014) Multi-parasite host susceptibility and multi-host parasite infectivity: a new approach of the Biompha-laria glabrata/Schistosoma mansoni compatibility polymorphism. Infect. Genet. Evol. 26, 80-88

46. Mitta, G. et al. (2012) Compatibility polymorphism in snail/schis-tosome interactions: from field to theory to molecular mecha-nisms. Dev. Comp. Immunol. 37, 1-8

47. Njiokou, F. et al. (2004) Experimental study of the compatibility between Schistosoma haematobium and two species of Bulinus in Cameroon. Bull. Soc. Pathol. Exot. 97, 43-46 48. Vera, C. et al. (1990) Genetic variability in the compatibility between Schistosoma haematobium and its potential vectors in Niger. Epidemiological implications. Trop. Med. Parasitol. 41, 143-148 
49. Capron, A. et al. (1965) Contribution à l'étude expérimentale de la bilharziose à Schistosoma haematobium. Bull. WHO 32, 755-778

50. Xavier, M.L. and de Azevedo, J.F. (1965) Susceptibility of Pla-norbarius metidjensis (Forbes) from the south of Portugal (Algarve) and Bulinus (Ph.) africanus from Portuguese Guinea to Schistosoma haematobium from the same overseas province. Ann. Inst. Med. Trop. (Lisboa) 22, 57-63

51. Southgate, V.R. et al. (1984) Is Planorbarius metidjensis compati-ble with Schistosoma haematobium and S. bovis? Bull. Soc. Pathol. Exot. 77, 409-506 52. Simoes, M. and De Medeiros, L. (1980) Verificaçao da suscepti-bilidatde de Planorbarius metidjensis e Bulinus contortus de Portugal ao Schistosoma haematobium de Angola. Garcia de Orta Ser. Zool. Lisboa 9, 67-70

53. Bettencourt, A. and Borges, I. (1922) Le Planorbis metidjensis, hôte intermédiaire du Schistosoma haematobium au Portugal. Confirmation expérimentale. Archives de I'Institut Bactériologie "Camara Pestana" Lisboa 5, 133-133

54. Moukrim, A. et al. (1995) A comparative study of the shedding of cercariae of Schistosoma haematobium in newborn Bulinus trun-catus. Parasitol. Res. 81, 537-539

55. Moukrim, A. et al. (1996) Schistosoma haematobium: influence of the number of miracidia on several characteristics of infection in newborn Planorbarius metidjensis. Parasitol. Res. 82, 267-269

56. Zekhnini, A. et al. (1997) Schistosoma haematobium: compara-tive studies on prevalence and cercarial shedding according to the shell diameter of Planorbarius metidjensis at miracidial exposure. Parasitol. Res. 83, 303-305

57. Zekhnini, A. et al. (2002) Effect of a short period of desiccation during the patent period on cercarial shedding of Schistosoma haematobium from Planorbarius metidjensis. Parasitol. Res. 88, 768-771

58. Yacoubi, B. et al. (1999) Schistosoma haematobium: compara-tive studies on the characteristics of infection in three populations of Planorbarius metidjensis from the Agadir province in South Morocco. Parasitol. Res. 85, 239-242

59. Mone, H. et al. (1999) The distribution of Schistosoma bovis Sonsino, 1876 in relation to intermediate host mollusc-parasite relationships. Adv. Parasitol. 44, 99-138

60. Webster, B.L. and Southgate, V.R. (2003) Compatibility of Schis-tosoma haematobium, S. intercalatum and their hybrids with Bulinus truncatus and B. forskalii. Parasitology 127, 231-242

61. Bremond, P. et al. (1993) Arguments for the modification of the genome (introgression) of the human parasite Schistosoma hae-matobium by genes from S. bovis, in Niger. C. R. Acad. Sci. III 316, 667-670

62. Mone, H. et al. (2015) Introgressive hybridizations of Schistosoma haematobium by Schistosoma bovis at the origin of the first case report of schistosomiasis in Corsica (France, Europe). Parasitol. Res. 114, 4127-4133

63. Huyse, T. et al. (2013) Hybridisation between the two major African schistosome species of humans. Int. J. Parasitol. 43, 687-689

64. Leger, E. et al. (2016) Introgressed animal schistosomes Schis-tosoma curassoni and S. bovis naturally infecting humans. Emerg. Infect. Dis. 22, 2212-2214

65. Leger, E. and Webster, J.P. (2017) Hybridizations within the Genus Schistosoma: implications for evolution, epidemiology and control. Parasitology 144 (1), 65-80 http://dx.doi.org/10.1017/ S0031182016001190 Epub 2016 Aug 30. PMID: 27572906

66. King, K.C. et al. (2015) Hybridization in parasites: consequences for adaptive evolution, pathogenesis, and public health in a changing world. PLoS Pathog. 11, e1005098

67. Stensgaard, A.S. et al. (2013) Large-scale determinants of intes-tinal schistosomiasis and intermediate host snail distribution across Africa: does climate matter? Acta Trop. 128, 378-390

68. McCreesh, N. and Booth, M. (2013) Challenges in predicting the effects of climate change on Schistosoma mansoni and Schis-tosoma haematobium transmission potential. Trends Parasitol. 29, 548-555 
69. Ittiprasert, W. and Knight, M. (2012) Reversing the resistance phenotype of the Biomphalaria glabrata snail host Schistosoma mansoni infection by temperature modulation. PLoS Pathog. 8 , e1002677

70. Simoonga, C. et al. (2009) Remote sensing, geographical infor-mation system and spatial analysis for schistosomiasis epidemi-ology and ecology in Africa. Parasitology 136, 1683-1693

71. Manyangadze, T. et al. (2016) Modelling the spatial and seasonal distribution of suitable habitats of schistosomiasis intermediate host snails using Maxent in Ndumo area, KwaZulu-Natal Prov-ince, South Africa. Parasites Vectors 9, 572

72. Bass, D. et al. (2015) Diverse applications of environmental DNA methods in parasitology. Trends Parasitol. 31, 499-513

73. Bohmann, K. et al. (2014) Environmental DNA for wildlife biology and biodiversity monitoring. Trends Ecol. Evol. 29, 358-367

74. Huver, J.R. et al. (2015) Development and application of an eDNA method to detect and quantify a pathogenic parasite in aquatic ecosystems. Ecol. Appl. 25, 991-1002

75. Schets, F.M. et al. (2010) Confirmation of the presence of Trichobilharzia by examination of water samples and snails following reports of cases of cercarial dermatitis. Parasitology 137, 77-83

76. Schneider, J. et al. (2016) Detection of invasive mosquito vectors using environmental DNA (eDNA) from water samples. PLoS One 11, e0162493

77. Hartikainen, H. et al. (2016) Assessing myxozoan presence and diversity using environmental DNA. Int. J. Parasitol. 46, 781-792

78. Stothard, J.R. et al. (2017) Towards interruption of schistosomi-asis transmission in sub-Saharan Africa: developing an appropri-ate environmental surveillance framework to guide and to support 'end game' interventions. Infect. Dis. Poverty 6, 10

79. Rowan, W.B. (1964) Sewage treatment and schistosome eggs. Am. J. Trop. Med. Hyg. 13, 572-576

80. Brady, O.J. et al. (2013) Modelling adult Aedes aegypti and Aedes albopictus survival at different temperatures in laboratory and field settings. Parasites Vectors 6, 351

81. Whitty, C.J. et al. (2000) Presentation and outcome of 1107 cases of schistosomiasis from Africa diagnosed in a non-endemic coun-try. Trans. R. Soc. Trop. Med. Hyg. 94, 531-534

82. Bierman, W.F. et al. (2005) Presentation and diagnosis of imported schistosomiasis: relevance of eosinophilia, microscopy for ova, and serology. J. Travel Med. 12, 9-13

83. Meltzer, E. et al. (2006) Schistosomiasis among travelers: new aspects of an old disease. Emerg. Infect. Dis. 12, 1696-1700

84. Van Gool, T. et al. (2002) Serodiagnosis of imported schistoso-miasis by a combination of a commercial indirect hemagglutina-tion test with Schistosoma mansoni adult worm antigens and an enzyme-linked immunosorbent assay with S. mansoni egg anti-gens. J. Clin. Microbiol. 40, 34323437

85. Jaureguiberry, S. et al. (2010) Acute schistosomiasis, a diagnostic and therapeutic challenge. Clin. Microbiol. Infect. 16, 225-231 Trends 


\section{Figure I.}

Total Number of Snails Recovered Weekly over Sites 5, 8, and 9 in the Cavu River from Week 24 (midJune) to Week 35 (end of August), 2016.

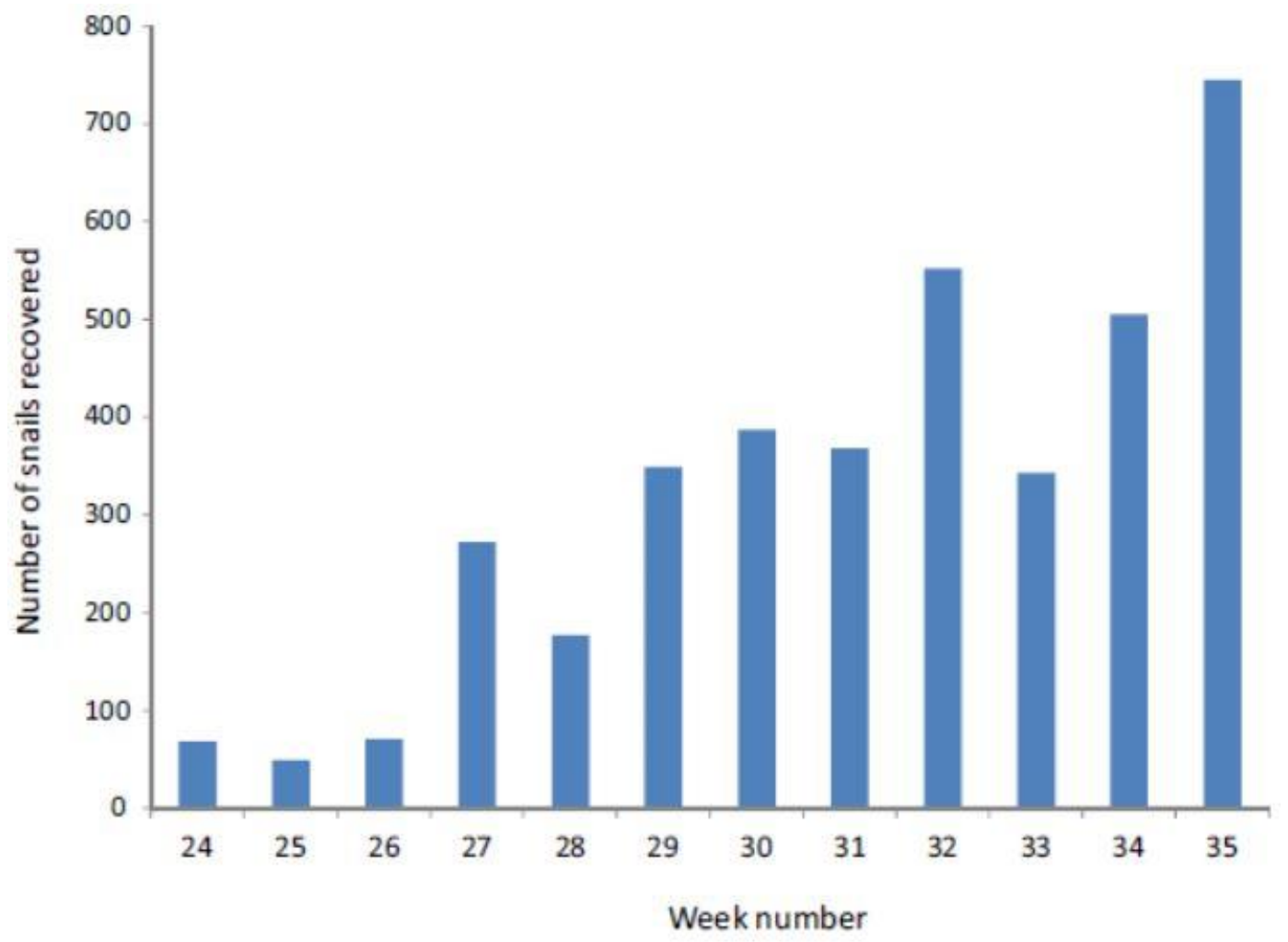




\section{BOX 1}

\section{Snail Fluctuation in Space and in Time in the Cavu River}

The Cavu River is where the parasite emerged in Corsica in both 2013 and 2015. For snail sampling, the river was divided into 9 sites corresponding to a transect of 200 to 300 meters long [17]. The contamination that occurred in 2013 concerned only upstream sites numbered 8 and 9 (2 out of 9 sites) [17]. Unexpectedly in 2015, patients were infected only at site 5 , where neither snails nor parasites had been recovered in 2013 [18]. During the same year, important variations in snail intensity were also observed weekly. Figure I shows the total number of snails recovered at sites 5,8 , and 9 in the summer of 2016, during the tourist season (same sampling effort in each site and for each week). The number of snails increased from 50 to 750 between mid-June (week 24) and the end of August (week 35), indicating that the snail population greatly increased during the tourist season. The presence of tourists is also at a maximum between mid-July and mid-August, thus potentially increasing the transmission risks.

\section{BOX 2}

\section{Imported Schistosomiasis: A Difficult Diagnosis}

Diagnosis of imported schistosomiasis may be compromised since these infections are asymptomatic in $30-50 \%$ of cases [81-83]. Once the medical diagnosis has been suspected, further laboratory diagnosis validation can also be difficult. Identifying eggs by microscopic examination of patient's urine is poorly sensitive (_20-30\%) since parasite load is often low [81-83]. Another difficulty specific to S. haematobium _ S. bovis hybrid infection is the possibility of eggs being excreted in urine and/or in faeces. Eggs of $\mathrm{S}$. haematobium and $\mathrm{S}$. bovis are classically excreted in urine and faeces, respectively. Whether hybrid eggs are preferentially (but not exclusively) excreted in urine, in faeces, or in both, is yet to be determined. In Corsica, only urines were examined, hence raising the possibility of having diagnosed false negatives. Altogether, these different points make diagnosis of imported cases of schistosomiasis difficult, especially for physicians from nonendemic countries who may not be aware of this tropical parasitic disease. Serodiagnosis is the tool of choice for screening and diagnosing of schistosomiasis, even when hybrids are present. Combining two techniques (enzyme-linked immunosorbent assay (ELISA), and indirect haemagglutination, i.e., IHA) raises the detection sensitivity up to $80-90 \%$ with an almost perfect specificity $\left(\_100 \%\right)[84,85]$. A Western blot from LDBio Diagnostics using S. haematobium and S. mansoni antigens is now available, ensuring optimum sensitivity and specificity in the case of discordant results (http://www.Idbiodiagnostics.com/fichiers_site/a1181ldb/contenu_pages/wb_sch_v18_fr_en.pdf). 


\section{Figure 1.}

Schistosomiasis Emergence in Europe: How Global Changes May Open Encounter and Compatibility Filters.

Schistosomes display two free larval stages during their lifecycle. The miracidia, which hatch from eggs excreted by a definitive vertebrate host in freshwater, then infest an intermediate snail host. The cercariae are released by a snail intermediate host in freshwater and infest definitive vertebrate hosts. Infestation of both the definitive and the intermediate hosts are conditioned by the opening of the encounter filter (i.e., the spatial and temporal overlap of the larvae and their future hosts) and the compatibility filter (i.e., hosts provide adequate resource and are incapable of eliminating the parasites). Global changes (e.g., climate changes, human activities) may synchronously open these two filters, hence facilitating parasites to accomplish their lifecycle in nonendemic countries.

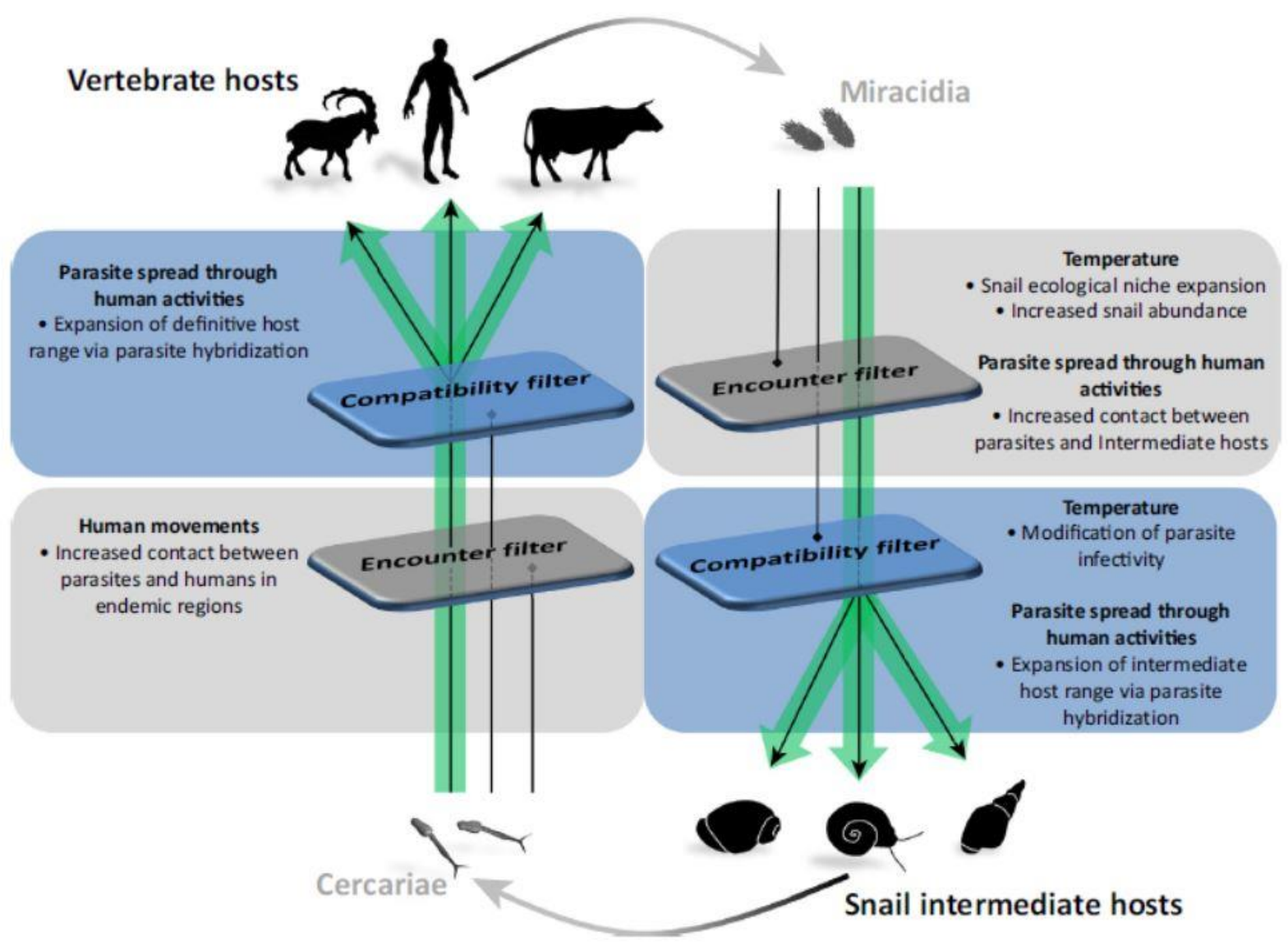

